\title{
A new radar-based system for detecting and tracking rockfall in open pit mines
}

\author{
A Michelini IDS GeoRadar s.r.l., Italy \\ F Viviani IDS GeoRadar s.r.l., Italy \\ M Bianchetti IDS GeoRadar s.r.l., Italy \\ N Coli IDS GeoRadar s.r.l., Italy \\ L Leoni IDS GeoRadar s.r.l., Italy \\ CJ Stopka IDS GeoRadar, USA
}

\begin{abstract}
Rockfalls present a major safety threat in open pit mining operations. The sudden onset of rockfall events makes it difficult, if not impossible, for conventional monitoring methods to provide adequate pre-warning, resulting in a challenge for mine operators and planners. One of the major challenges for geotechnical engineers is the ability to model the trajectory and run-out distances of rock blocks in order to properly map the risks associated to the occurrence of such events and to properly design catch benches and exclusion zones.

Several modelling tools are available today for this purpose but they are often poorly supported and calibrated with instrumental data. One of the most common methods currently used consists of localising the detachment and accumulating areas by comparing 3D models generated by LiDAR scans. The major drawback of this method is that the information that is collected is post-event and cannot provide data about the dynamics of the rockfall event. IDS GeoRadar has recently developed an innovative radar system able to locate and track rockfalls in real-time from a distance several hundred metres from the slope by simultaneous coverage of a wide portion of the highwall. The new radar detection system is able to generate quick alerts immediately after the detachment of the initial rock blocks and will provide beneficial information with regards to statistical data on the occurrence in space and time, travel path, velocity, runout distance, and size of blocks.
\end{abstract}

Keywords: rockfall, monitoring, safety

\section{Introduction}

Rockfalls are a natural hazard process that occurs on rock slopes, both natural and man-made, and consists of the detachment of a single or multiple rock blocks, followed by a rapid downward motion characterised by free-falling, bouncing, rolling, and sliding phases (Turner \& Jayaprakash 2013).

In open pit mining operations, rockfalls present a major threat to safety due to the potentially high kinetic energies attained by the boulders along the travel path. Even small rock fragments weighing only a few kilograms can cause fatal injuries to personnel, while larger rockfall events involving more than a few hundred tons of material may cause major damage to mining equipment and facilities. Rockfalls can have a major economic impact when production is temporarily stopped for safety reason.

In these heavily trafficked areas, rockfall hazards need to be effectively managed through the combined application of an early warning system (EWS) and mitigation measures (Girard 2001). When discussing the effectiveness of an EWS for rockfall hazards (Sättele 2015), the hazard event stages and the corresponding systems used in hazard management are shown in Figure 1. 


\section{Hazard Event Stages}

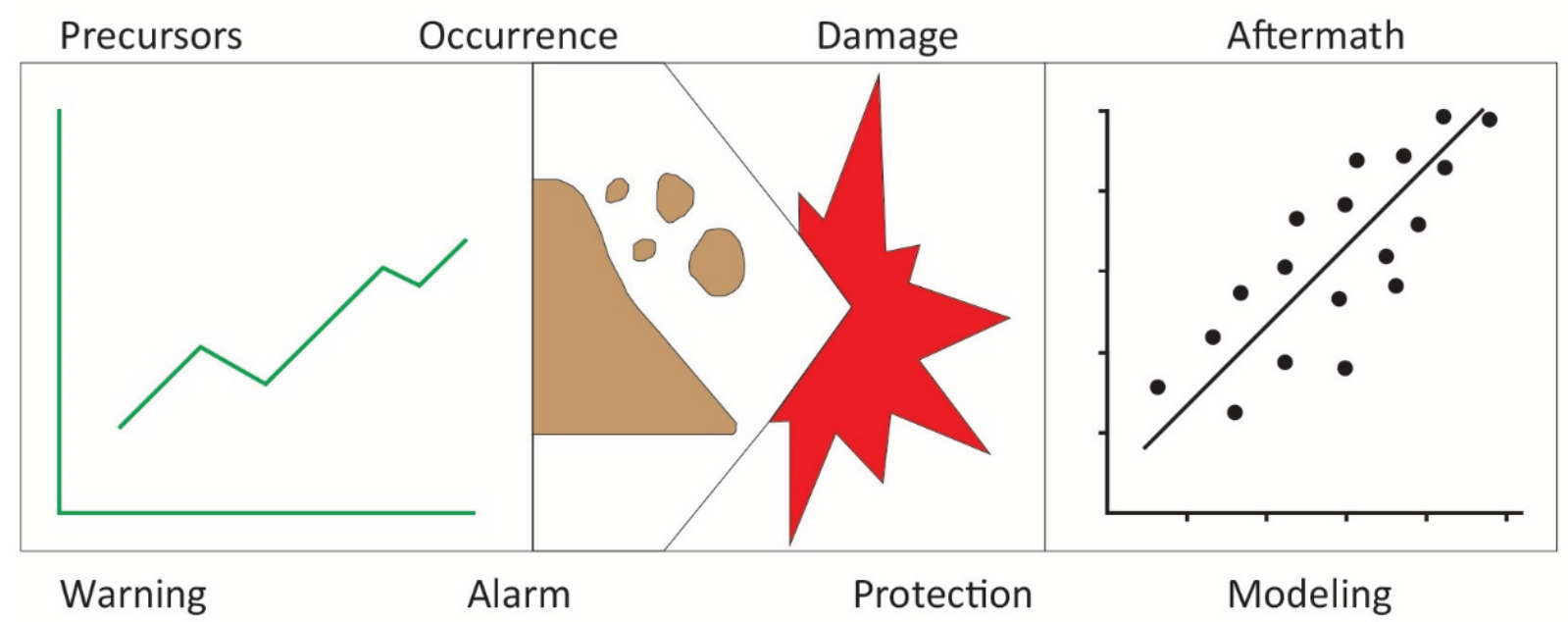

\section{Systems Exploited}

Figure 1 Workflow of the hazard event management system

\subsection{Monitoring of slopes and rockfall}

The essential elements of any open pit mine slope monitoring strategy may include a combination of the following:

- Daily visual inspections.

- Crack metres.

- Photogrammetry.

- Microseismics.

- Survey prisms.

- Laser scanners.

- Radar.

None of these methods should be used in isolation and the choice of which combination to use is dependent on, amongst other things, the quality and structure of the rock mass, pit design, quality of mining, seismic regime, and climate.

Since the introduction of interferometric radar monitoring into the open pit mining industry in 2003, near real-time broad slope monitoring is possible. Interferometric radars are able to measure rock surface movement with sub-millimetric accuracy and today, are an essential tool of a slope monitoring strategy. Interferometric radar does, however, suffer from the disadvantage of being very challenging to predict the onset of a rockfall. Rockfall typically occurs without warning although minor ravelling on a highwall or movement of small amounts of sand between individual rocks could be precursors to a rockfall. In addition, rockfall displays the characteristics of a brittle failure. Typical precursors of ductile and brittle failures are listed in Table 1.

To illustrate quantitatively the difference between independent ductile and brittle failures occurring in the same mine pit which has been measured by an IBIS-FM slope monitoring radar system (Figure 2 and Table 1), presented here are the ductile and brittle deformation time series and ductile and brittle failure measured precursors respectively. 
The first event (ductile failure) is dominated by a marked plastic deformation (Figure 2) and was triggered by a rainstorm that ended three days later with a large slope failure. The radar provided sufficient pre-warning allowing the area to be evacuated prior to the failure (Ramsden et al. 2015).

Table 1 Ductile and brittle failure precursors

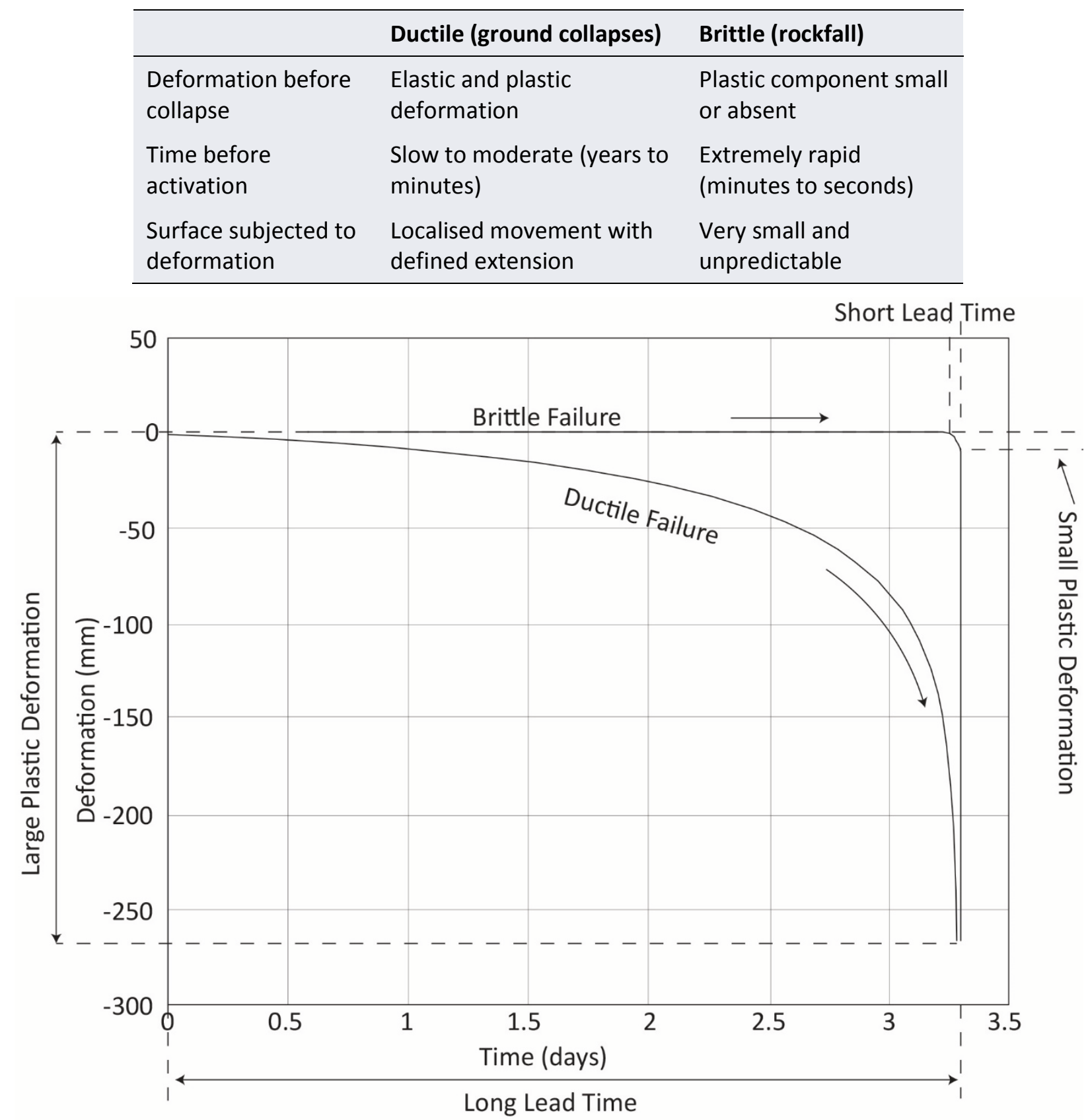

Figure 2 Ductile and brittle deformation time series

The second event (brittle failure) is dominated by a marked brittle trend and was triggered by a blasting operation that ended as a small rockfall event that developed in just 30 minutes from onset to collapse. Initial deformation was detected by the radar, however, setting up proper alarm thresholds for these types of events is challenging. The measured precursor deformations for both events are listed in Table 2.

For smaller rockfall events, the precursor deformations could be even less, with total deformation less than $1 \mathrm{~mm}$ and surface involving less than $10 \mathrm{~m}^{2}$ making it difficult to detect with standard sensors used for deformation monitoring, especially at long distances. For rockfall, the sudden initiation of an event makes it 
extremely difficult to provide pre-warning of an imminent event prior to rock detachment. In those mine pits where rockfall has been identified as a major hazard, it will be necessary to rethink the operating strategy of the EWS specifically related to rockfall (Meier et al. 2017; Sättele 2015). With respect to the hazard event management (Figure 1), it is apparent that for rockfall hazard management, a system for detecting and measuring rockfall events with an automatic alarm system integrated into the warning system will be extremely beneficial in the open pit mining environment and heavily trafficked and relied on transportation corridors.

Table 2 Ductile and brittle failure measured precursors

\begin{tabular}{lll}
\hline & Slope failure & Rockfall \\
\hline Total deformation before failure & $\sim 300 \mathrm{~mm}$ & $\sim 1.5 \mathrm{~mm}$ \\
Time before failure & $\sim 80 \mathrm{~h}$ & $\sim 0.25 \mathrm{~h}$ \\
Surface subjected to deformation & $\sim 15,000 \mathrm{~m}^{2}$ & $\sim 10 \mathrm{~m}^{2}$ \\
\hline
\end{tabular}

\subsection{Rockfall modelling}

In addition to the EWS issues discussed, one of the major challenges for geotechnical engineers is the ability to model the trajectory and run-out distances of rockfalls. This information is important in designing effective catch benches, the design of rockfall mitigation such as catch fences, and to accurately determine exclusion zones of a pit that are most prone to rockfall. Due to their nature, interferometric radars are not capable of tracking rockfalls and recording the travel path of rockfalls in real-time. At present, rockfall hazard rating systems rely heavily on pit wall visual inspection and depending on the individual inspector, the final rating can vary significantly.

Several proprietary software modelling tools are available today to model rockfall. Their input parameters are typically derived from generic rock-type data and often do not accurately represent the onsite rock characteristics. In order to obtain accurate input data, it is necessary to throw rock blocks of various sizes usually from the pit crest and to determine those velocities and trajectories by photographic means. These exercises need to be repeated on various rock types and in different areas of the pit/s and can be extremely time-consuming. One of the most common methods currently used to obtain rockfall data consists of localising the detachment and accumulating areas by comparing 3D models generated by LiDAR scans (Abellán et al. 2010). The major drawback of this method is that the information which is collected is post-event (deferred data) and does not provide data about the dynamics of the rockfall event, for example, the trajectory of the falling rocks down a pit slope or the bounce heights.

\subsection{Rockfall detector radar}

To overcome some of the discussed limitations in rockfall hazard management, IDS GeoRadar has recently developed a frequency modulated continuous wave Doppler radar (RockSpot). The RockSpot radar (Figure 3) will detect and track rockfall events in real-time. The operating principle of this sensor is to transmit and receive microwave signals within a fixed field-of-view and to detect the frequency variations induced by moving targets via the well-known Doppler effect (Figure 4). The sensor specifications are summarised in Table 3. For each moving target detected, the sensor is also able to measure the corresponding distance, azimuth, and velocity allowing for real-time tracking of targets of interest.

Through the sensitivity of the sensor, RockSpot is able to generate quick alerts immediately after the detachment of the first rock block has occurred and can therefore, be efficiently integrated with an alarm system with automatic activation of acoustic signals, traffic lights, barriers, and alerts via email and SMS service to dispatch. In addition, RockSpot can also provide useful information in terms of statistical data on the occurrence of rockfalls in space and time, travel path, front velocity, and area of extension that can then be used to calibrate modelling tools and properly dimension containments, catch benches, and exclusion zones. 


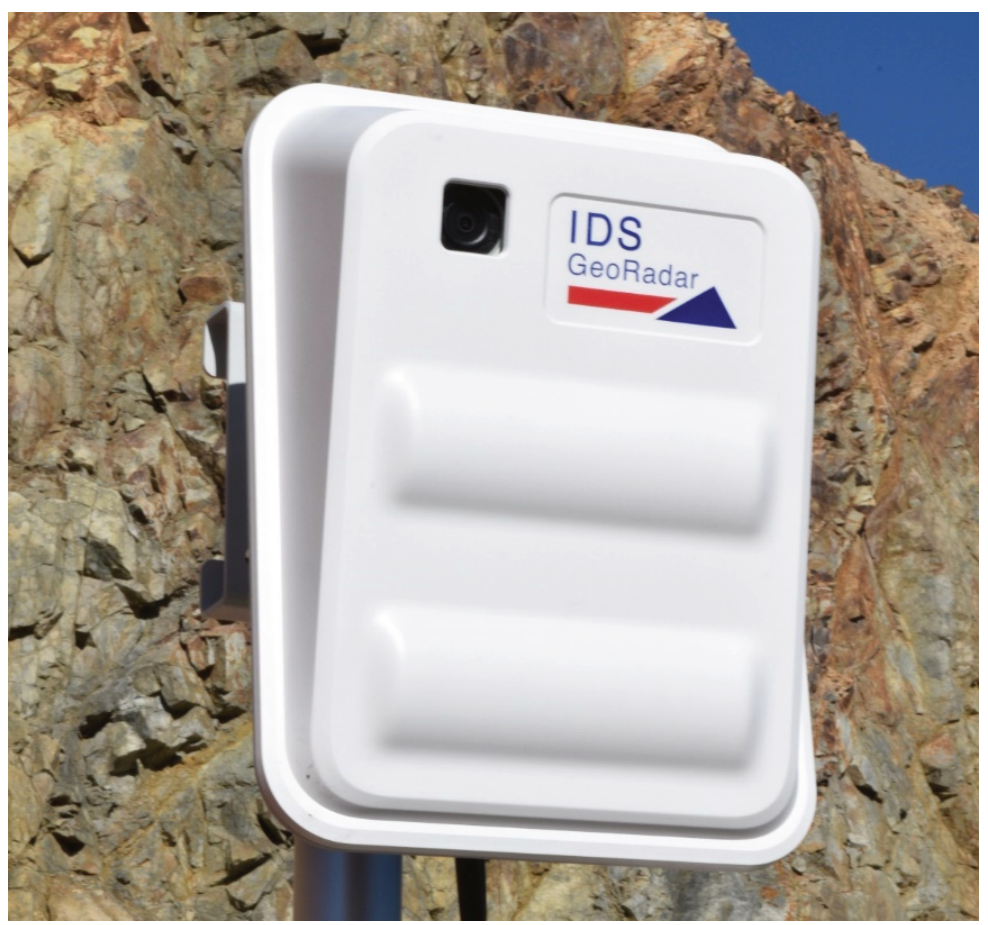

Figure 3 RockSpot survey unit

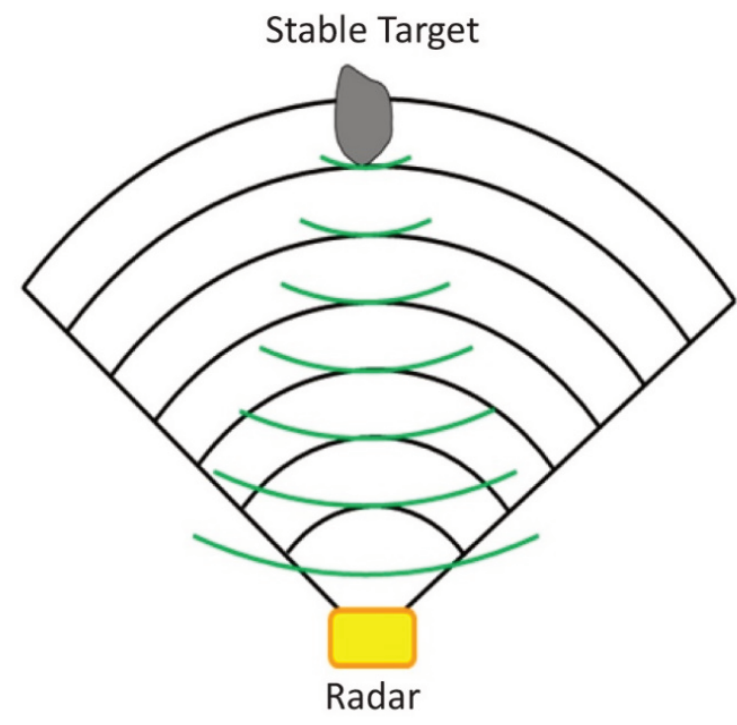

(a)

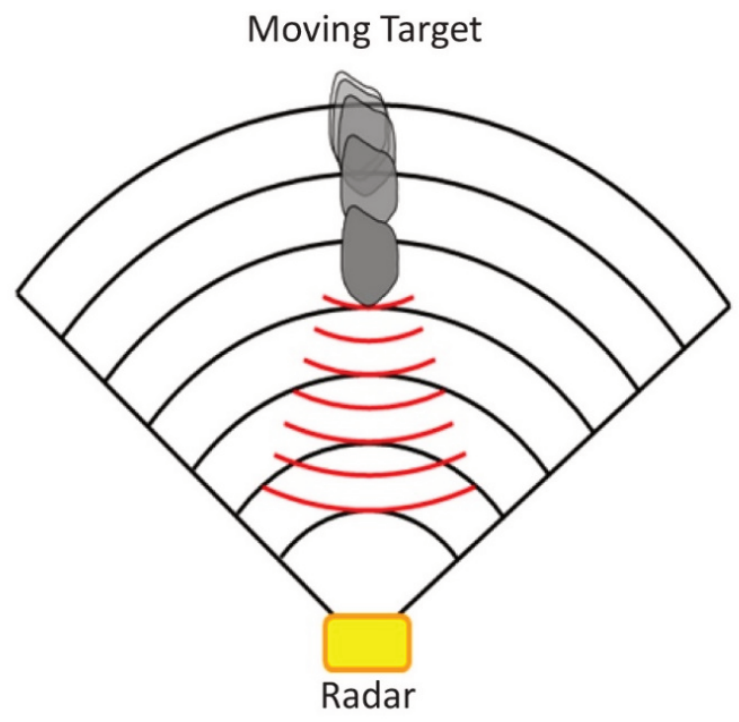

(b)

Figure 4 Radar Doppler effect operating principle. (a) A steady target doesn't induce any frequency variation in the backscattered signal, while (b) a moving target induces a frequency shift in the backscattered signal

Table 3 Sensor specifications

\begin{tabular}{ll}
\hline & Technical specifications \\
\hline Operating range & $50-2,000 \mathrm{~m}$ \\
Field-of-view & $80^{\circ}$ azimuth, 40 elevation \\
Tracking range resolution & $4 \mathrm{~m}$ \\
Tracking azimuth accuracy & $1^{\circ}$ \\
\hline
\end{tabular}




\section{$2 \quad$ Application cases}

\subsection{Natural slopes}

A natural slope located on a road to Oberalppass, Switzerland, near the Swiss settlement of Tschamut, was selected to conduct early tests of RockSpot. Rocks were released over a $2 \mathrm{~m}$ vertical drop and travelled down a $40^{\circ}$ slope composed of sections of alpine meadow, rocks, and scrub vegetation which was then followed by a runout zone composed of a near horizontal alpine meadow. The total height difference was about $45 \mathrm{~m}$ (Figure 5). The RockSpot was installed directly in front of the release zone.

The rocks used for the controlled test comprised of eight granite rocks, $20-50 \mathrm{~cm}$ in size, and weighed about $30-50 \mathrm{~kg}$. The individual rock specifications are presented in Table 4. The rock drops took place over five rounds (eight rocks in each round) for a total of 40 independent rock drops.

RockSpot successfully detected all 40 rockfall drops. Three-dimensional rockfall trajectories were obtained by draping the RockSpot data over a digital terrain model (DTM) of the slope (Figure 6). In additional to the rockfall trajectories, RockSpot was also able to determine individual rock velocities along the travel path. The round four results are summarised in Table 5.

\subsection{Mining slopes}

RockSpot was installed in a hard rock copper mine at an average distance of $1,000 \mathrm{~m}$ from the pit wall (Figure 7). The pit size is approximately $1,950 \mathrm{~m}$ by $1,650 \mathrm{~m}$ and $700 \mathrm{~m}$ deep. Bench height is $15 \mathrm{~m}$ with overall slope angles between $45-48^{\circ}$.

The mine has already deployed two IBIS-FM interferometric radar systems integrated through the Full Pit Monitoring 360 TrueVector platform, as well as geodetical (TPS) and geotechnical sensors. The two IBIS-FM systems are used by the geotechnical team for early warning on impending slope failures and providing adequate coverage and resolution to identify slope movements at the sub-bench and multi-bench scales.

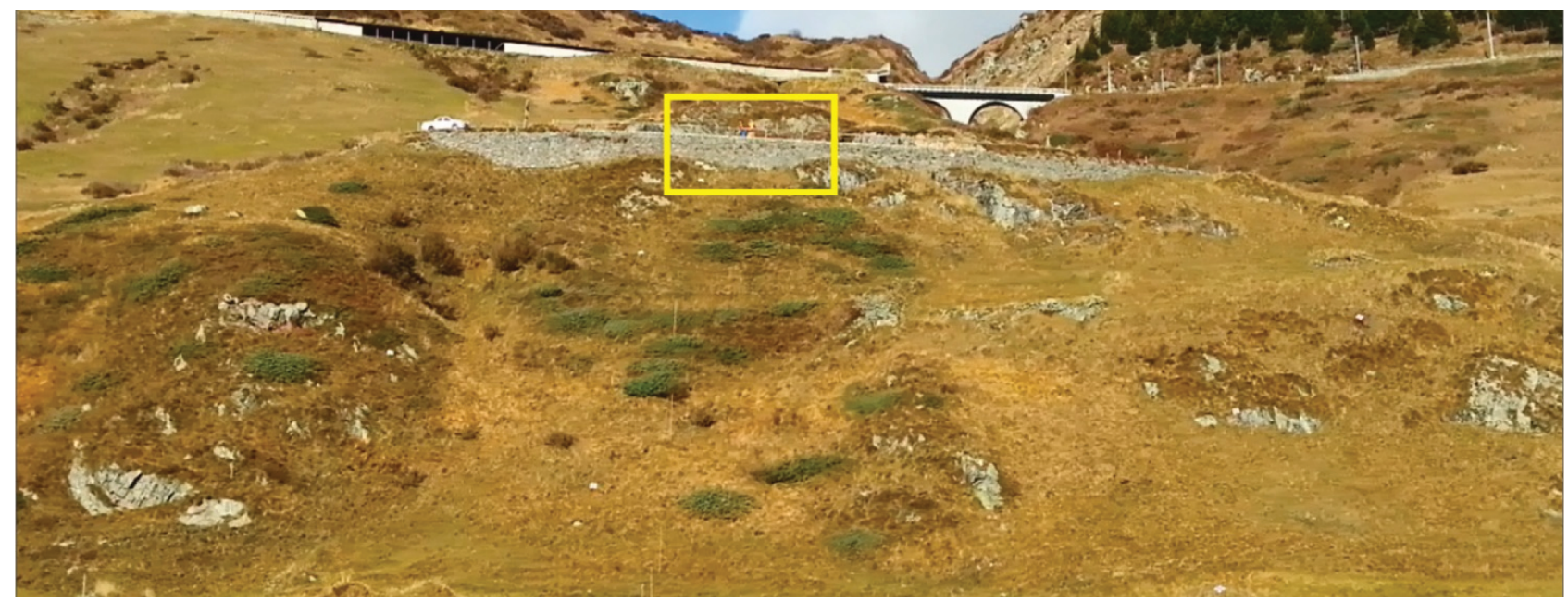

Figure 5 Field test site. View from rockfall radar, Tschamut, Switzerland. Rock release location in yellow 
Table 4 Field test rocks specifications

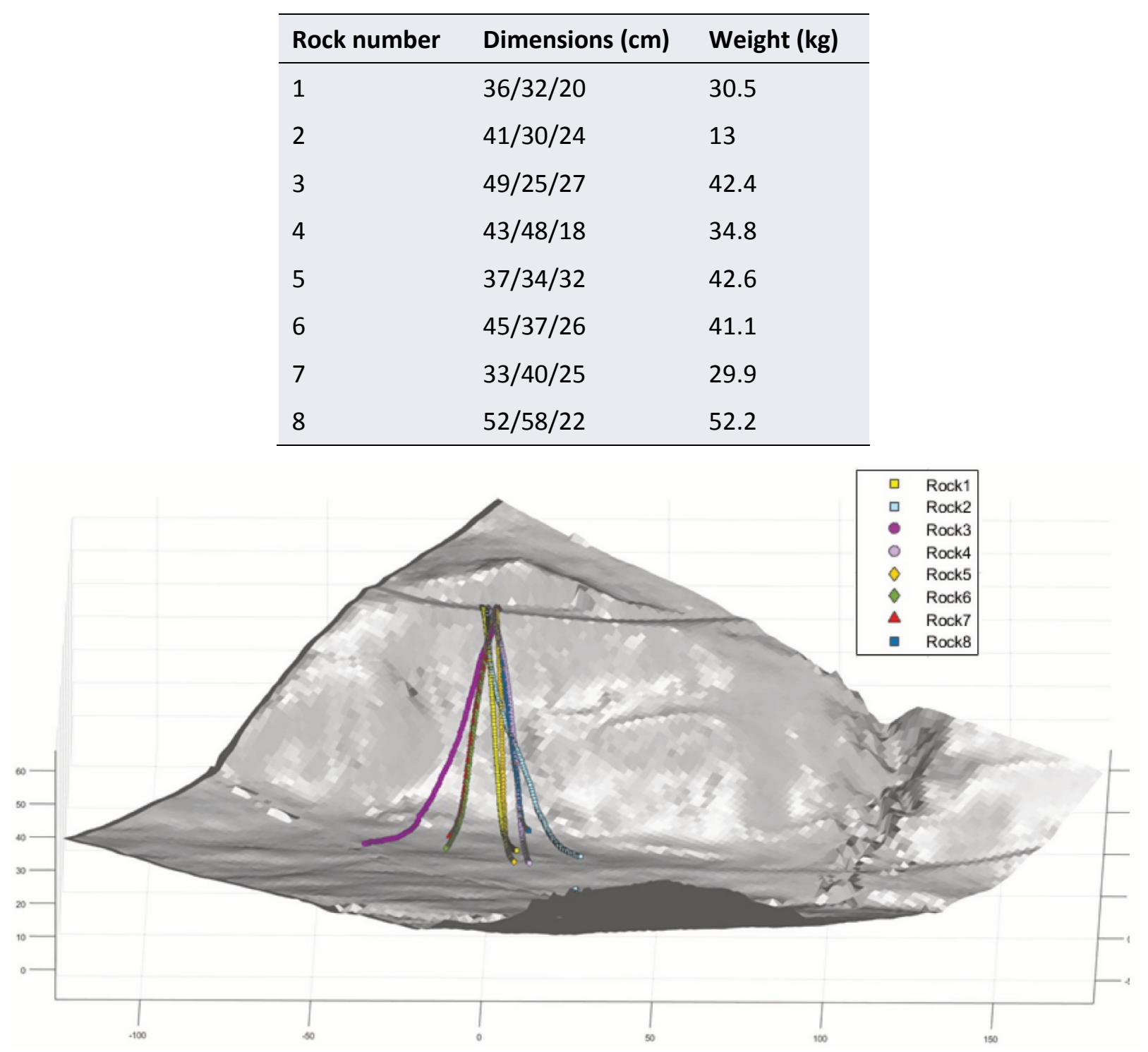

Figure 6 Field test results, round four 3D path draped over the scenario digital terrain model

Table 5 Round four field test radar measurement results

\begin{tabular}{llll}
\hline $\begin{array}{l}\text { Rock } \\
\text { number }\end{array}$ & $\begin{array}{l}\text { Horizontal travel } \\
\text { distance }(\mathbf{m})\end{array}$ & Duration $(\mathbf{s})$ & $\begin{array}{l}\text { Maximum } \\
\text { velocity }(\mathrm{m} / \mathrm{s})\end{array}$ \\
\hline 1 & 95 & 14.7 & 12.5 \\
2 & 102 & 17.2 & 12.4 \\
3 & 100 & 13.2 & 15.7 \\
4 & 106 & 17.2 & 14.8 \\
5 & 106 & 16 & 14.2 \\
6 & 94 & 12.1 & 15.2 \\
7 & 83 & 13.1 & 12.3 \\
8 & 71 & 16.9 & 8.1 \\
\hline
\end{tabular}




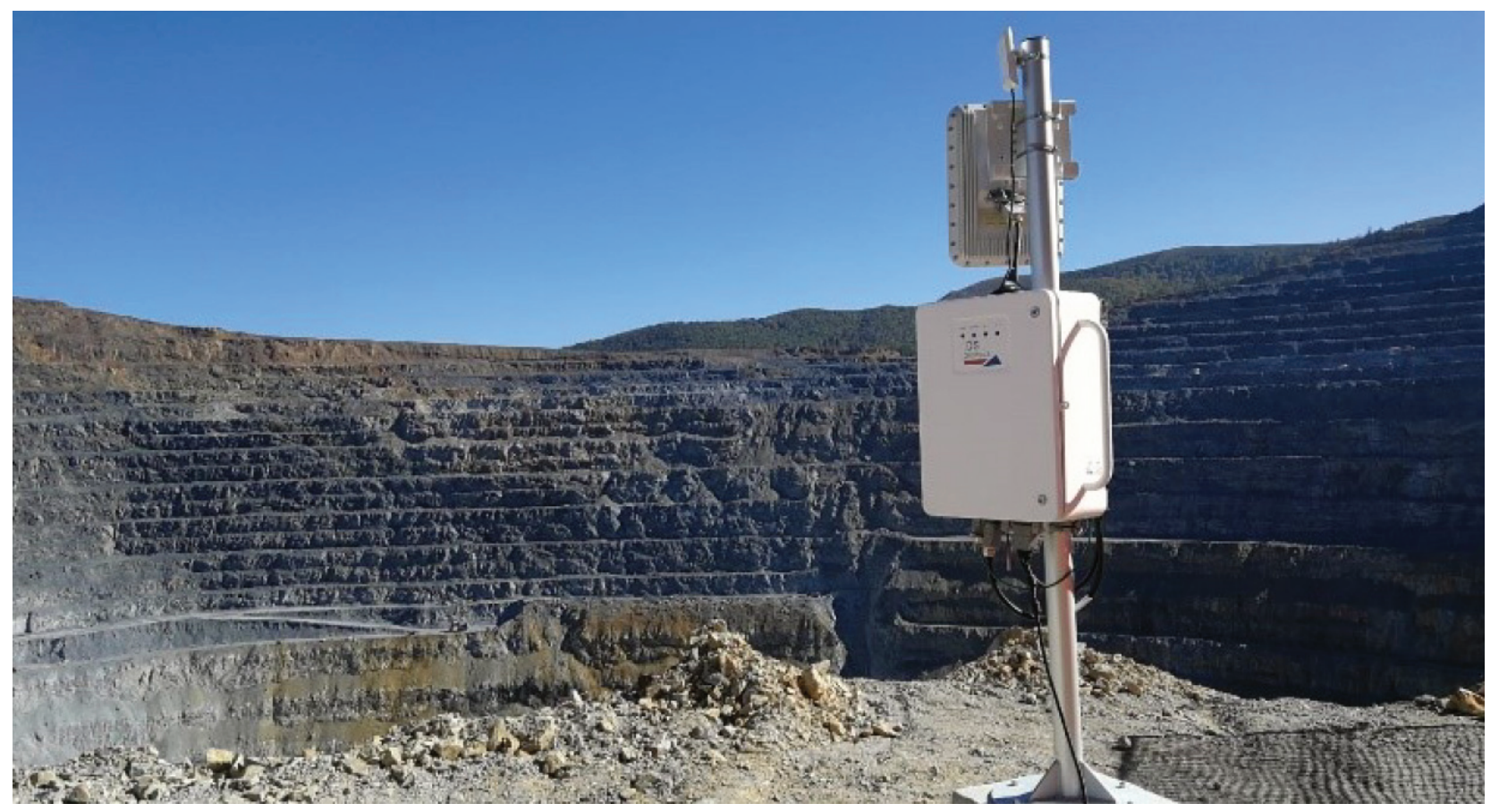

Figure 7 RockSpot radar ground mounted and monitoring the mine wall

The brittle nature of the rock mass and the steep slope angle make the occurrence of rockfalls very frequent posing a real threat to worker safety and mining operations. From the installation position, the RockSpot is able to monitor the entire eastern wall of the pit.

In order to assess the radar performance, five rocks were released from an inter-ramp working area located approximately at half pit depth. The chosen rocks were of various sizes and shapes to simulate real rockfall shapes and conditions (Figure 8). It must be noted that in real conditions, rockfalls are often characterised by the simultaneous ravelling of several rock boulders and therefore, a single-rock release represents a worst-case scenario for the radar.

Before the test execution, the GPS positions and the sizes of the five marked boulders were measured in order to have the 2D size and precise position of the release point of each rock. RockSpot was able to successfully detect and track the five controlled rockfalls (Table 6). Travel path and runout distances have been recorded and stored in the server database. From the proprietary application GeoCloud, it is possible to retrieve information about every single tracked rockfall event picked up by the radar and examine all the relevant parameters (runout distance on the DTM, duration of the rockfall event, and average velocity), as well as the intensity and front velocity heat maps (Figure 9).

\section{Conclusion}

A new rockfall detector radar has been developed by IDS GeoRadar to detect and track rockfalls in real-time. The main features of the system are the ability to:

1. Identify the occurrence and location of rockfall.

2. Provide real-time alerts on rockfall.

3. Determine the area extension and velocities of the individual rockfall events.

4. Determine and plot the trajectory of falling rocks down a slope.

5. Determine individual rock runout distance at the base of a slope.

6. Determine zones in a pit which are most prone to rockfall which can allow mine engineers to design appropriate rockfall mitigation measures. 
These features, when paired with an alarm system embedded in the radar software, can contribute greatly to improving open pit safety, thereby adding to the capabilities of a standard interferometric slope monitoring radar system. The alarm-fitted RockSpot can automatically trigger safety procedures like closure of roads (if linked to a traffic light or to a lighting barrier) or the instantaneous generation of alerts through sirens and communications to dispatch.

Data analysis can provide useful statistical information for multiple events and for different sectors of a pit in support of risk evaluation and mitigation measurements.
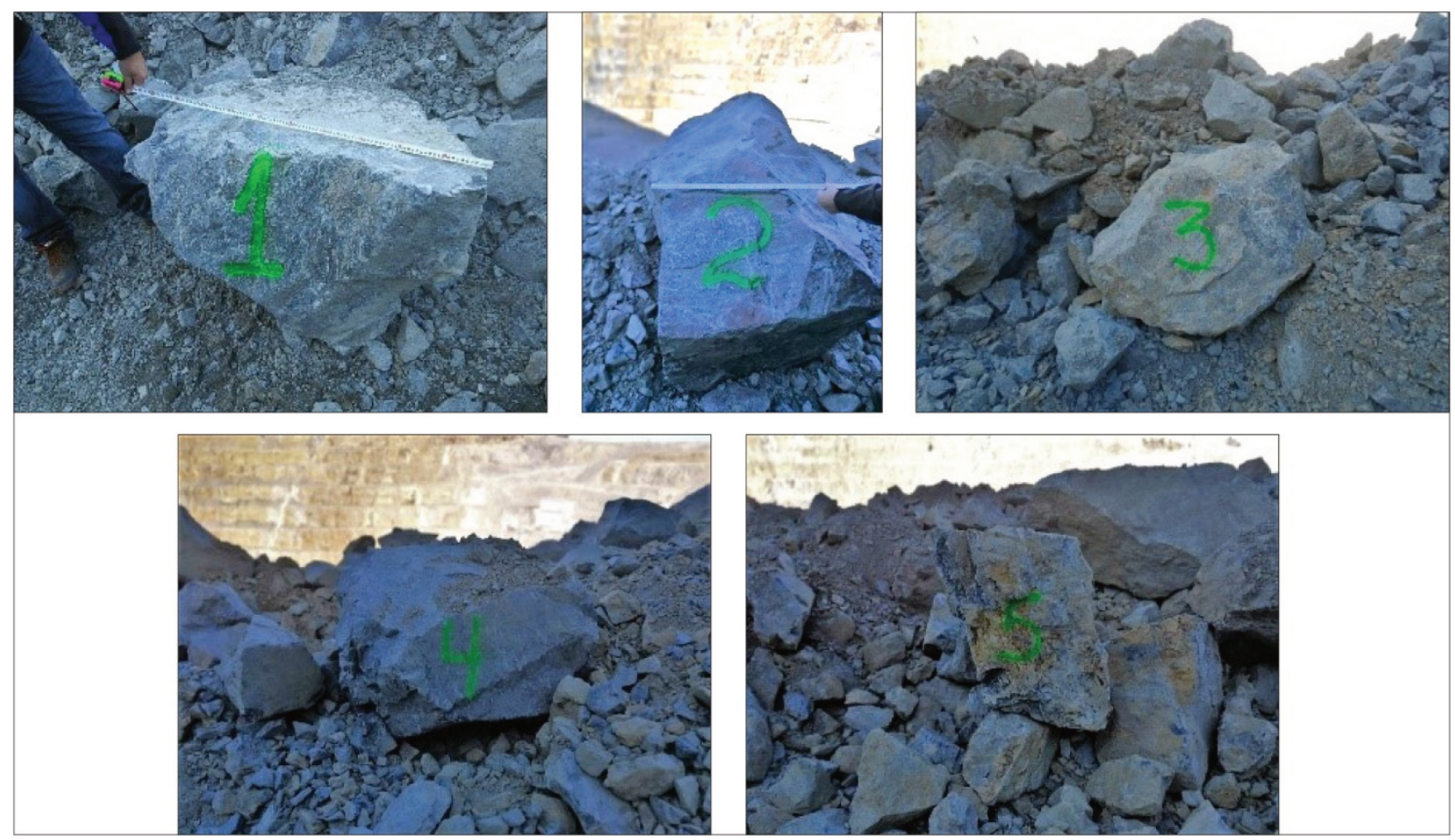

Figure 8 Rocks released from slope

Table 6 Rock specifications and rockfall tests results

\begin{tabular}{lllll}
\hline Rock number & Dimensions $(\mathbf{c m})$ & Runout $(\mathbf{m})$ & Duration $(\mathbf{s})$ & Velocity $(\mathbf{m} / \mathbf{s})$ \\
\hline 1 & $100 \times 60$ & 284 & 15.5 & 18.30 \\
2 & $150 \times 80$ & 276 & 15.0 & 18.40 \\
3 & $120 \times 80$ & 150 & 7.5 & 20.00 \\
4 & $110 \times 90$ & 171 & 8.7 & 19.62 \\
5 & $110 \times 60$ & 146 & 8.9 & 16.40 \\
\hline
\end{tabular}




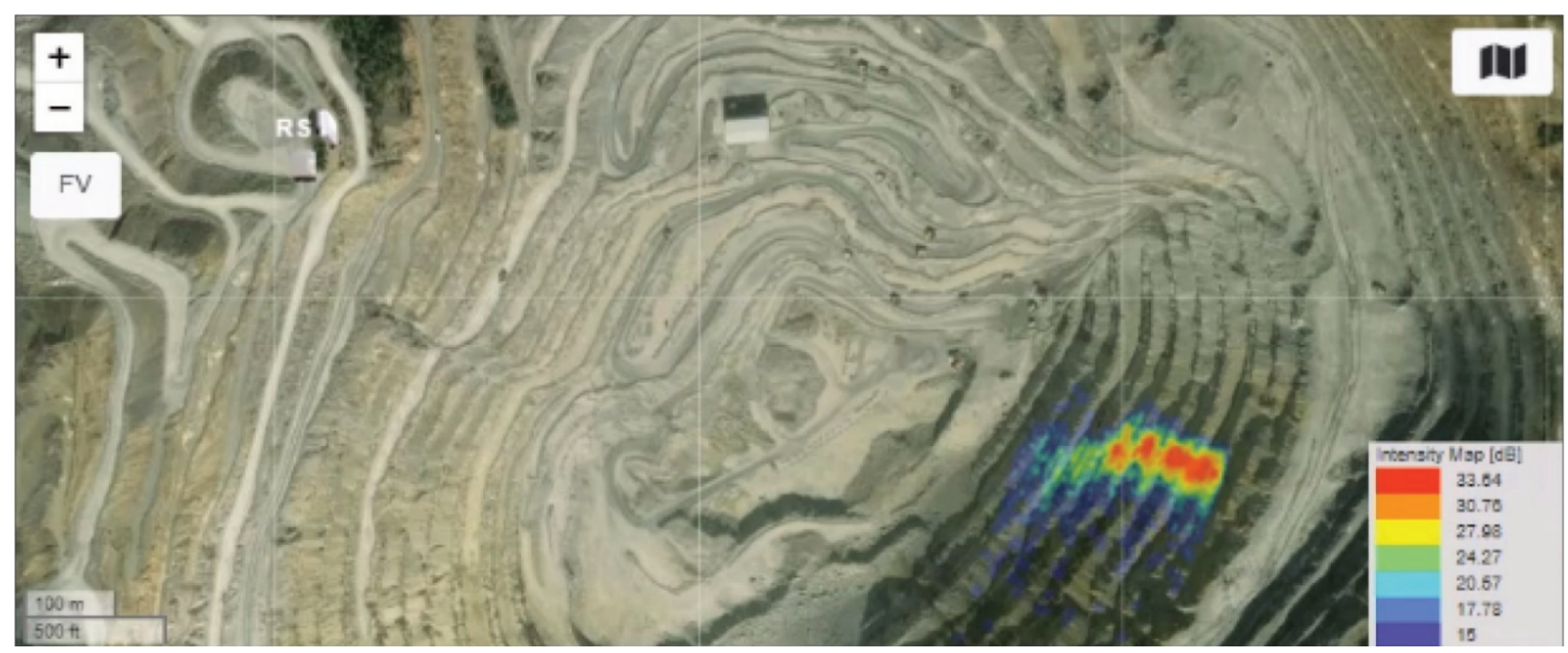

(a)

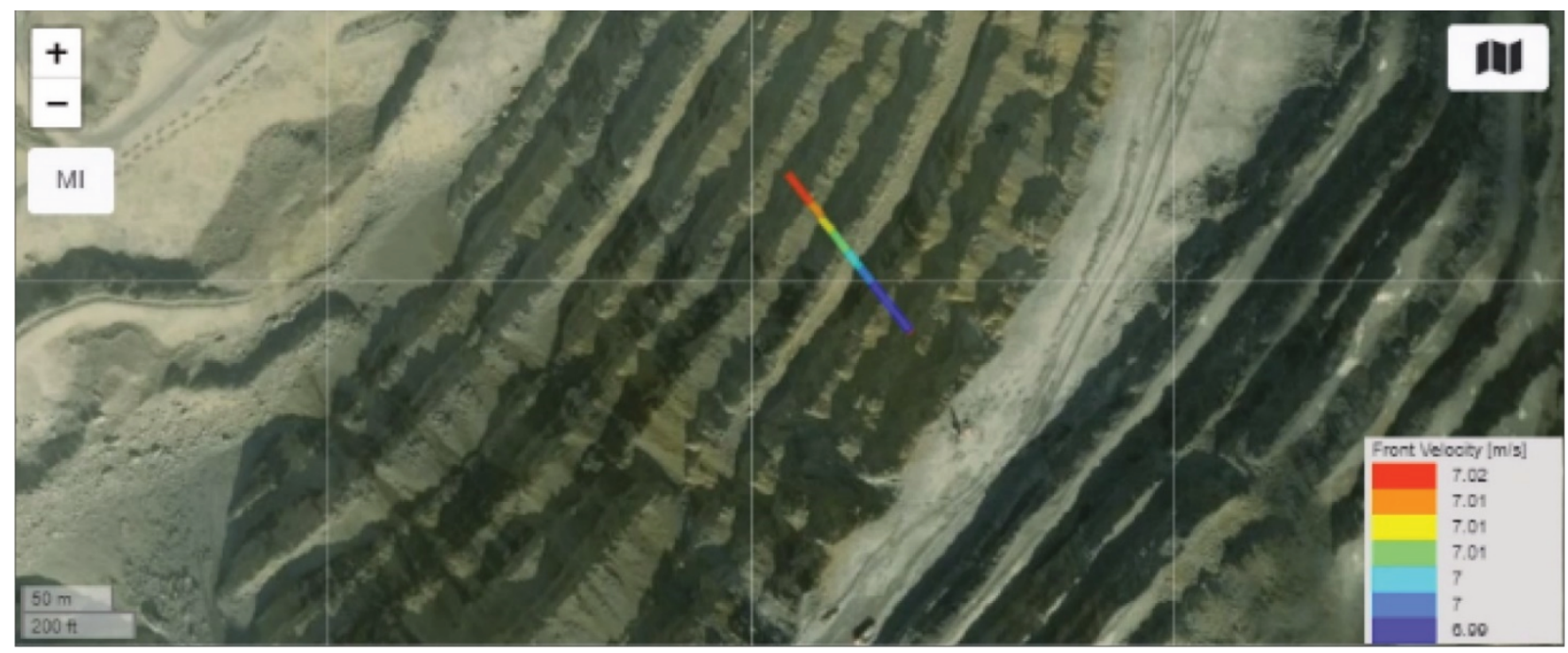

(b)

Figure 9 Intensity heat map (a); and frontal velocity heat map (b) displayed on aerial photos of rock \#2 drop test visualised in GeoCloud

\section{References}

Abellán, A, Calvet, J, Vilaplana, JM \& Blanchard, J 2010, 'Detection and spatial prediction of rockfalls by means of terrestrial laser scanning monitoring', Journal Geomorphology, vol. 119, pp. 162-171.

Girard, JM 2001, 'Assessing and monitoring open pit mine highwalls', 32nd Annual Institute on Mining Health, Safety and Research, pp. 159-171.

Meier, L, Jacquemart, M, Wahlen, S \& Blattmann, B 2017, 'Real-time rockfall detection with doppler radars', in J Corominas (ed.), Proceedings of the 6th Interdisciplinary Workshop of Rockfall Protection, CIMNE, Barcelona, pp. 75-78.

Ramsden, F, Coli, N, Benedetti, Al, Falomi, A, Leoni, L \& Michelini, A 2015, 'Effective use of slope monitoring radar to predict a slope failure at Jwaneng Mine, Botswana', Proceedings of the 2015 International Symposium on Slope Stability in Open Pit Mining and Civil Engineering, The Southern African Institute of Mining and Metallurgy, Johannesburg.

Sättele, M 2015, Quantifying the reliability and effectiveness of early warning systems for natural hazards, PhD Thesis, Technical University of Munich, Munich.

Turner, AK \& Jayaprakask, GP 2013, 'Rockfall: characterization and control', New TRB Publication, vol. 284, pp. 39-41, http://onlinepubs.trb.org/onlinepubs/trnews/trnews284Rockfall.pdf 